nach unten umgebogenes Rohr angebracht, welches mittelst eines Kautschukschlauches mit einem Quecksilberniveaugefäss verbunden ist.

Auf dem horizontalen Brett ist neben jedem Schenkel des Urohres: eine Millimeterscala angebracht. Man stellt zunächst das Quecksilbergefäss hoch, bringt in eines der becherförmigen Gefässchen den zu untersuchenden Körper, schliesst beide Gefässchen und senkt das Quecksilbergefäss. Liest man nün den Quecksilberstand in beiden Schenkeln ab, so kann man, wenn man das Volumen der Becher, sowie den einem Millimeter entsprechenden Rauminhalt der Schenkel des Urohres kennt, das Volumen des zu untersuchenden Körpers berechnen.

Der Verfasser gibt an, wie man experimentell das Volumen der Becher bestimmt, und wie sich auch dann das Princip verwenden lässt, wenn die beiden Becher nicht genau gleich gross sind, respective nicht beide Schenkel in ihrer ganzen Länge gleiches Caliber zeigen, sondern nur einer dieser Bedingung genügt ist.

Hinsichtlich dieser Punkte sei auf das Original verwiesen.

Ein hochgradiges Quecksilberthermometer, das bis zu $575^{\circ}$ benutzt werden kann, ohne zu erweichen oder sonstige Mängel aufzuweisen, stellt W. Niehls ${ }^{1}$ ) aus Jenaer Hartglas, Härtegrad 8, her. Dieses Thermometer übertrifft somit das früher besprochene aus Borosilicatglas hergestellte. $\left.{ }^{2}\right)$ Statt des Stickstoffs, der nach dem Verfasser über $30^{\circ}$ sich nicht mehr recht eignen soll, wird hier Kohlensäure benutzt, um das Quecksilber unter Druck zu halten und so sein Sieden zu verhindern.

Bei dieser Gelegenheit verfehle ich nicht auf einen Vortrag, den

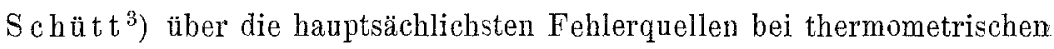
Messungen im Berliner Bezirksvereins des Vereins deutscher Chemiker gehalten hat, hinzuweisen.

\title{
Einen Apparat znr Bereitung grosser Schwefelwasserstoffmengen
} hat W. P. Bradle $y^{4}$ ) angegeben.

Eine weithalsige $16 l$ fassende Flasche mit nahe am Boden befindlichem, seitlichem Tubulus wird mit Schwefeleisen beschickt.

Der Tubulus trägt ein mittelst eines Quetschbahns verschlossenes Ablaufrohr für die verbrauchte Säure. Der Hals der Flasche ist mit einem doppelt durchbohrten Stopfen verschlossen, der einerseits das

1) Berg- und Hüttenmännische Zeitung 58, 141.

2) Vergl. diese Zeitschrift 36, 178.

3) Zeitschrift f. angew. Chemie 1897, s. 96.

4) American chemical Journal 21, 370. 